\title{
EFFECT OF BLASTING ON THE STABILITY OF LINING DURING EXCAVATION OF NEW TUNNEL NEAR THE EXISTING TUNNEL
}

\author{
Tran Tuan Minh'1, Nguyen Quang Huy²
}

1. Hanoi University of Mining and Geology, Underground and mining construction department, Ha Noi city, Vietnam; tuanminhhumg@yahoo.com

2. Institute of transport science and technology, Bridge and Tunnel design department, Ha Noi city, Vietnam; quanghuy170687@gmail.com

\begin{abstract}
In recent years, experimental and numerical researches on the effect of blasting pressure on the stability of existing tunnels was widely obtained. However, the effect of the blasting pressure during excavation a new tunnel or expansion old tunnels on an existing tunnel has disadvantages and still unclear. Some researches were carried out to study the relationship of the observed Peak Particle Velocity (PPV) on the lining areas along the existing tunnel direction, due to either the lack of in situ test data or the difficulty in conducting field tests, particularly for tunnels that are usually old and vulnerable after several decades of service. This paper introduces using numerical methods with the field data investigations on the effect of the blasting in a new tunnel on the surrounding rock mass and on the existing tunnel. The research results show that not only predicting the tunnel lining damage zone under the impact of blast loads but also determination peak maximum of explosion at the same time at the surface of tunnel working.
\end{abstract}

\section{KEYWORDS}

Blasting vibration, Tunnels, Drilling and blasting method, Existing tunnels

\section{INTRODUCTION}

The effects of drilling and blasting in case of excavation of new tunnels or expansion old tunnels near the existing tunnels along of the express way from North to South of Vietnam such as tunnels in the Hai Van pass tunnel project, Cu Mong tunnel, Deo Ca tunnel, etc are obtained. Traditional excavation method was widely used during excavation tunnels through the mountains in Vietnam in [1], this method has advantages for economy conditions, workers and engineers in Vietnam. In the past the researches for the stability of rock mass around transported tunnels and the assessments of the effects of tunnel blasting on the existing tunnels and buildings were carried out by not only authors in Vietnam such as in [2], [3], [4], [5], [6-7], [8-9] but also other authors in the world in [10], [11], [12], [13], and [14]. Researches in Vietnam are obtained for the stability of buildings on the surface of the ground, the assessment standard only for buildings during blasting on the open pit mining [3].

In the recent years some researches were carried out using physical models to study the effect of blasting vibration on an existing tunnel in [6-7], [8], and [9]. Smith et al presented the results of experimental studies carried out at small scale into the propagation of blast waves along straight tunnels roughened by means of different-sized roughness elements fixed along the two model tunnels sides. The results indicated that the use of rough-walled tunnels could provide an efficient protective solution to a sensitive structure. Previous publications have indicated that the 
strongest vibrations of the existing tunnel lining occur on the side closest to the blasting centre and are proportional to the maximum segmental explosive charge instead of the total charge. Rock masses with harder rock and fewer discontinuities seem to contribute to stronger tunnel vibrations than softer rock and more discontinuities. However, a few researches were carried out to study the relationship of the blasting pressure values on the displacements and internal forces in lining of existing tunnels. It is therefore necessary to find appropriated solutions for drilling and blasting to avoid damage to the lining of existing tunnels also normal operation of old tunnels. In this paper there is introduced the research on the changing of internal forces in lining of old tunnels with other the values of blasting pressures in geological conditions of Co Ma, Deo Ca and Hai Van Pass projects.

\section{NUMERICAL MODELING OF DEO CA TUNNEL PROJECT BASED ON THE SEISMIC COEFICIENTS $\left(K_{c}\right)$}

\section{Introduction of the project}

Deo Ca project consists of total length $13.4 \mathrm{~km}$, twin tunnels with each tunnel $3.9 \mathrm{~km}$, the distance between two tunnels is $30 \mathrm{~m}$. According to the investor, Deo Ca Investment Joint Stock Company, it will take vehicles just over 10 minutes to pass through the tunnel, instead of travelling around 60 minutes through the pass. Vehicles using the tunnel can avoid rockslides, which often occur in the rainy season. With a total length of $13.19 \mathrm{~km}$, the Deo Ca Tunnel consists of the 4.12 $\mathrm{km}$ Deo Ca Tunnel and the existing $500 \mathrm{~m}$ Co Ma Tunnel. The two-lane tunnel is said to be installed with most modern equipment in Vietnam so far and vehicles can travel at $80 \mathrm{~km} / \mathrm{h}$. Bridges and roads leading to the two tunnels have a combined length of over nine kilometres. The project costs over VND11 trillion (USD485.2 million).

Deo Ca Tunnel will help boost trade and tourism in the central region in addition to creating a link between Phu Yen's Nam Phu Yen and Khanh Hoa's Van Phong. The Deo Ca Tunnel, which was put into operation in August 2017, is the second longest mountain road tunnel in the country, after the Hai Van Tunnel, which is 6.28 kilometres long and runs between Thua Thien in Hue Province and Da Nang City.

\section{Geological conditions}

The tunnels were excavated in the granite and gneiss layers with uniaxial compressive strengths higher than $100 \mathrm{MPa}$, using drilling and blasting method. Because of the changing of the level of top mountains along the direction of tunnel, hence in this study using numerical modelling for typical sections in case of R2B rock mass, the granite layers with RMR $>60$. The geological conditions can be seen as in Table 1. Planning profile and geological conditions of Deo Ca tunnel are seen as in the (Figures1-3). 
Tab. 1 - Properties of rock mass

\begin{tabular}{|l|c|}
\hline Parameters & Siltstone \\
\hline Unit weight of rock $\gamma, \mathrm{MN} / \mathrm{m}^{3}$ & 0.026 \\
\hline $\begin{array}{l}\text { Uniaxial compressive strength of intact rock } \sigma_{\mathrm{ci}}, \\
\mathrm{MPa}\end{array}$ & 80 \\
\hline Tensile strength $\sigma_{\mathrm{t}}, \mathrm{MPa}$ & 0.5 \\
\hline Cohesion $\mathrm{c}, \mathrm{MPa}$ & 2 \\
\hline Friction angle $\varphi$ & 40 \\
\hline Young modulus $\mathrm{E}, \mathrm{MPa}$ & 2500 \\
\hline Poisson ratio $\mathrm{V}$ & 0.3 \\
\hline Dilation angle $\psi$, degree & 0 \\
\hline Residual friction angle $\mathrm{c}_{\mathrm{re}}$, degree & 30 \\
\hline Span of roadways $\mathrm{B}, \mathrm{m}$ & 13.2 \\
\hline Height of tunnels $\mathrm{H}, \mathrm{m}$ & 9.5 \\
\hline
\end{tabular}
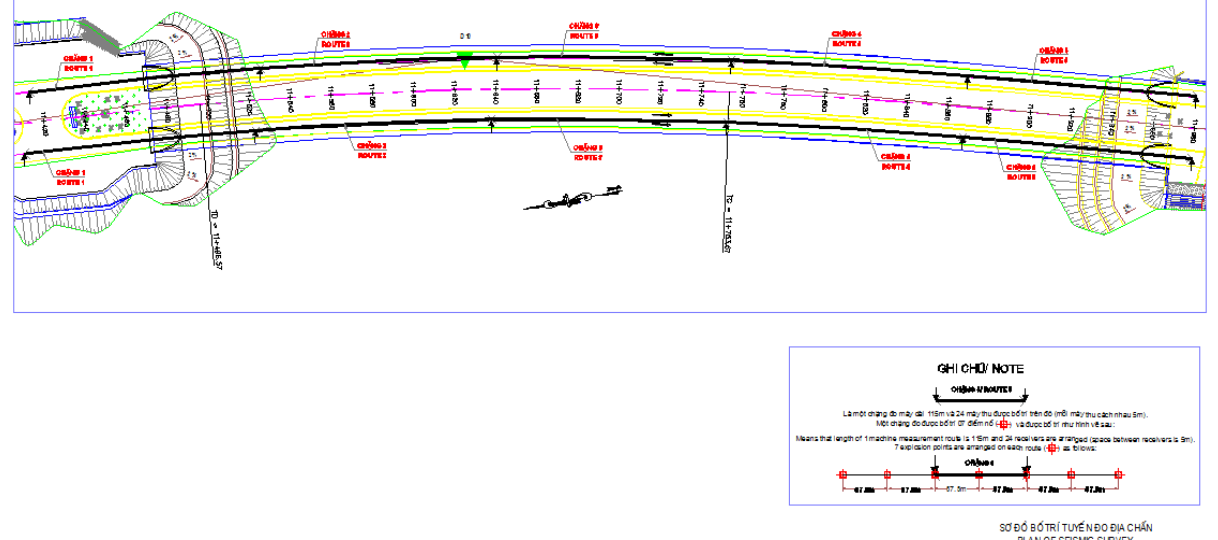

Fig. 1 - Planning profile of Deo Ca tunnel

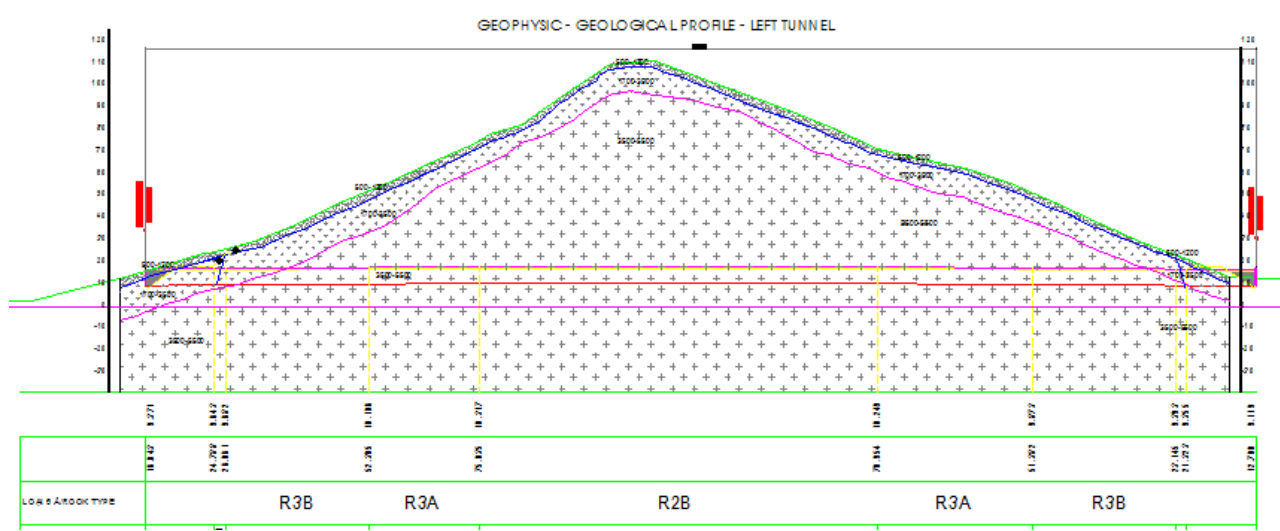

Fig. 2 - Geological profile of Deo Ca tunnel 

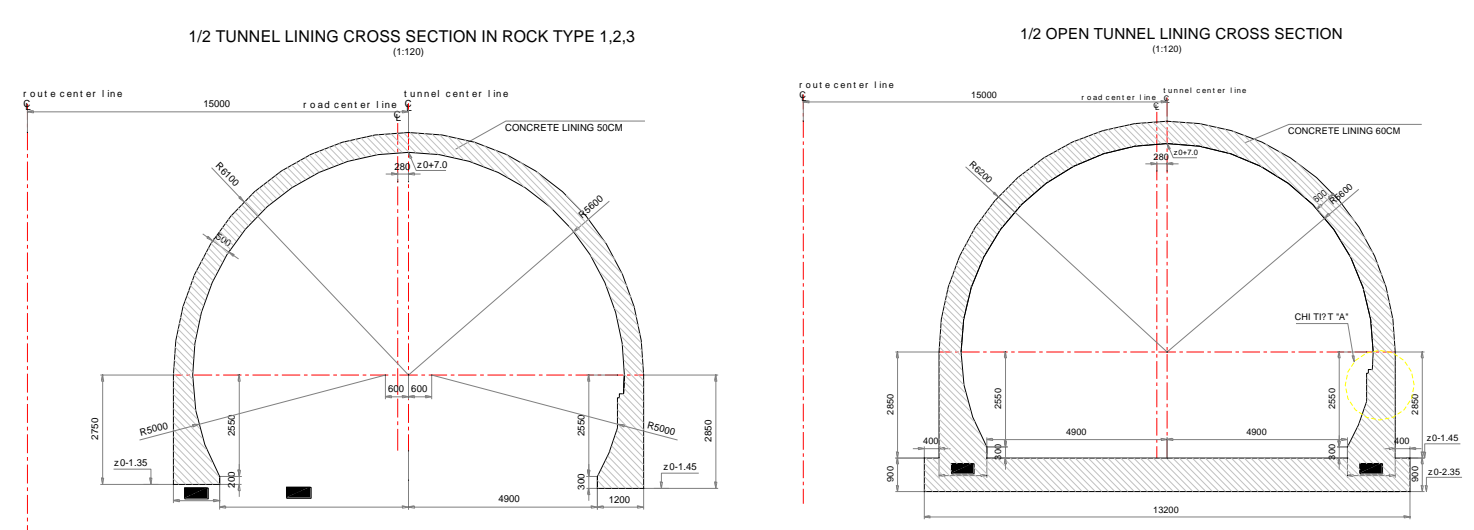

Fig. 3 - Profile of two tunnels

\section{Numerical modelling}

In this section, the simulation results obtained from Phase 2 (i.e. Rock and Soil 2dimensional analysis program) are presented due to it is believed to be an effective method for support design which has been widely used in mining engineering, especially in terms of the deformation mechanics of surrounding rock mass. The length of the numeric model is $113.2 \mathrm{~m}$ and the height $66.5 \mathrm{~m}$ respectively. The all boundaries of the model are applied to the fixed conditions to simulate the real application.

The supports used by rock bolts with diameter of bolts $\mathrm{d}=22 \mathrm{~mm}$; Young modulus of steel in rock bolts $E=200000 \mathrm{MPa}$; tensile capacity of bolts $-0.15 \mathrm{MN}$; out of plane spacing of bolts $1.5 \mathrm{~m}$; in plane spacing of bolts $1.5 \mathrm{~m}$. The length of bolts can be defined based on the radius of plastic zone around tunnels, here length of bolts $L=3500 \mathrm{~mm}$. Existing tunnels supported by concrete liner with the thickness $350 \mathrm{~mm}$, rebar of steel $\mathrm{d}=22 \mathrm{~mm}$; spacing of rebar $250 \mathrm{~mm}$.

Blasting pressures are applied in the model by using seismic loading coefficient by formula:

$$
\mathrm{P}=\mathrm{K}_{\mathrm{c} \cdot \gamma}
$$

Here $\mathrm{K}_{\mathrm{c}}$ - seismic coefficient; $\gamma$ - body forces of rock mass.

The Seismic coefficients are dimensionless coefficients which represent the (maximum) earthquake acceleration as a fraction of the acceleration due to gravity. Typical values are in the range of 0.1 to 0.3 . In this study we used the range values of $\mathrm{K}_{\mathrm{c}}=0.1 ; 0.2 ; 0.3 ; 0.4 ; 0.5 ; 0.6$ respectively.

Based on numerical method with using Phase 2 and seismic coefficient can be received model (Figure 4) and the result of displacement vectors of rock mass around tunnel as in the (Figure 5). Using results of numerical method can be established the relationship between the stress and displacements of rock mass on the boundary of existing tunnels and the changing of seismic coefficient, bending moment of concrete lining with other values of seismic coefficients. The results can be seen as in the (Figures 6-8).

The research results indicate that the values on the vertical axis which located in the left corner of existing tunnels, the minimum displacements located in the rightwall of the old tunnel respectively, besides the maximum values of displacements are investigated on the floor near the left corner of existing tunnels. Basing the assessment standards for the stability of tunnels can show that if the values of displacements of rock mass around tunnels and concrete lining are bigger than limited values, the concrete lining will be cracked. The results of research also show that it is necessary to use some solutions for blasting technologies to reduce blasting vibration on the existing tunnel. 


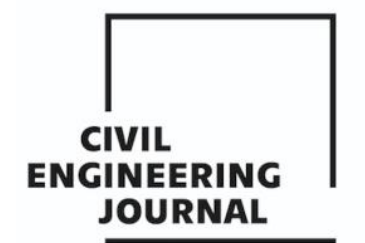

Article no. 4

THE CIVIL ENGINEERING JOURNAL 1-2021 OURNAL

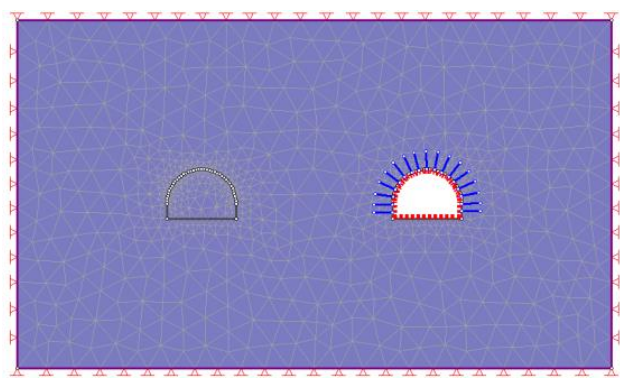

(a) The initial model

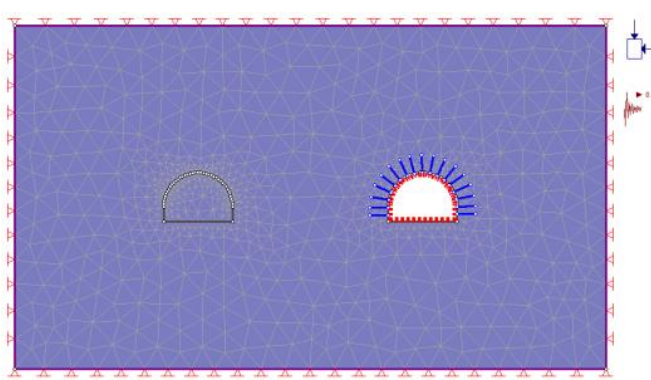

(b) Model using seismic loading coefficients

Fig.4 - Blasting model new tunnel near the existing tunnels

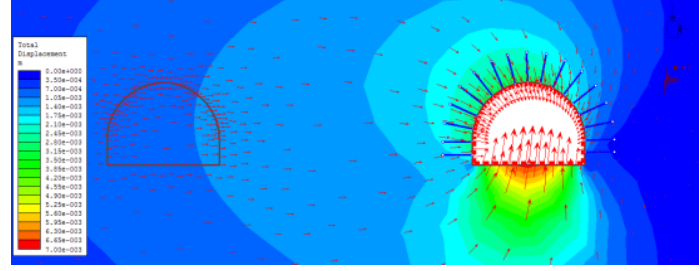

(a) Displacement vector in case of seismic coefficient $K_{c}=0.1$

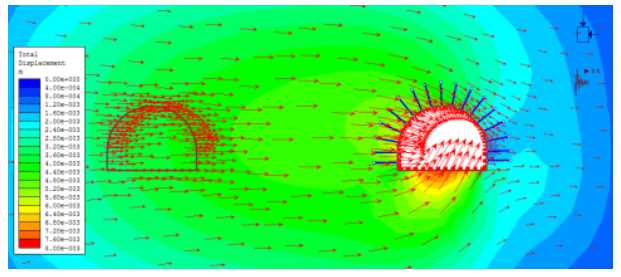

(b) Displacement vector with the seismic coefficient $K_{c}=0.5$

Fig. 5 - Displacement vector of rock mass around tunnels

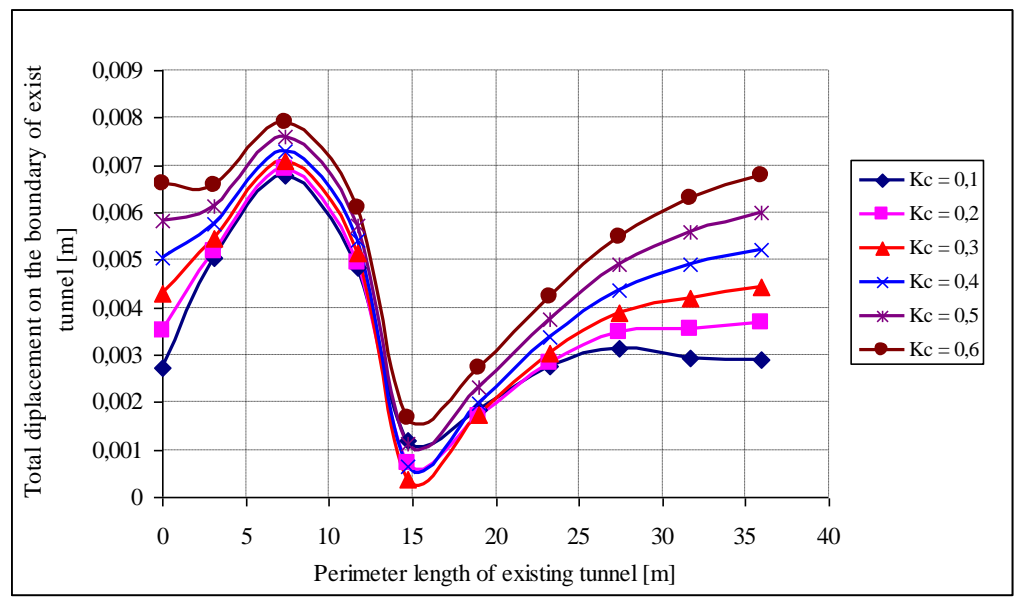

Fig. 6 - The changing of displacements of rock mass around existing tunnel 


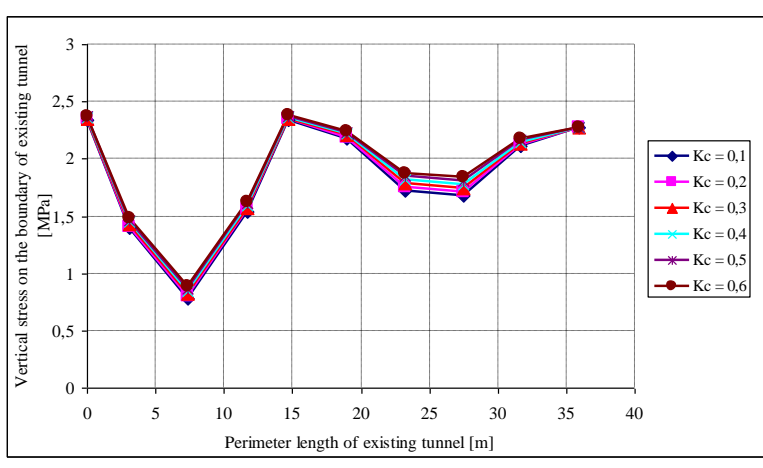

Fig. 7 - The relationship between stress around existing tunnels and $K_{c}$

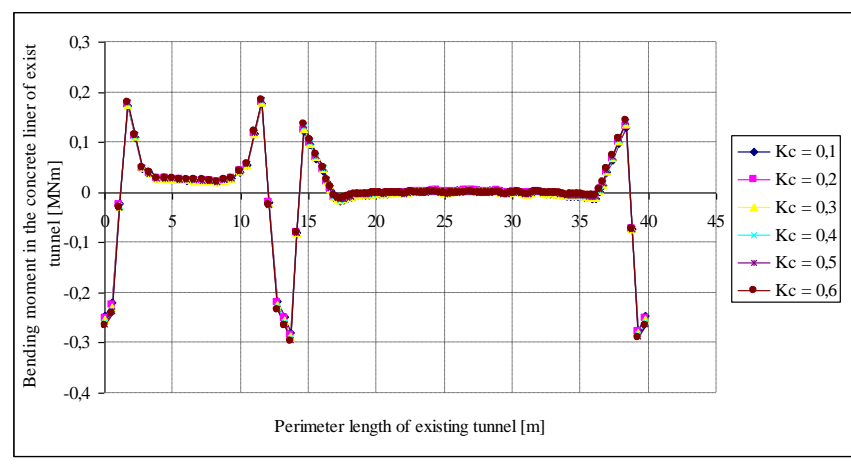

Fig. 8 - Bending moment in concrete lining of existing tunnel with other values of $K_{c}$

\section{NUMERICAL MODELING USING EQUIVALENT BLASTING PRESSURE FOR COMA TUNNEL PASS PROJECT}

The Co Ma Tunnel is a 2 tube tunnel that was built as a part of the Ca pass tunnel and road project to reduce the travel distance for commuters by $8 \mathrm{~km}$ between the Khanh Hoa and Phu Yen provinces and to help them avoid landslides during the rainy season.

Opened in September 2015, vehicles can travel at a maximum speed of $80 \mathrm{~km}$ per hour through this $500 \mathrm{~m}$ long tunnel. The tunnel operators wanted an energy-efficient lighting solution that would ensure the safety and comfort for all users at all times.

The supports used by rock bolts with diameter of bolt $\mathrm{d}=22 \mathrm{~mm}$; Young modulus of steel in rock bolts $\mathrm{E}=200000 \mathrm{MPa}$; tensile capacity of bolts $-0.15 \mathrm{MN}$; out of plane spacing of bolts -1.5 $\mathrm{m}$; in plane spacing of bolts $1.5 \mathrm{~m}$. The length of bolts can be defined based on radius of plastic zone around tunnels, here length of bolts $L=3500 \mathrm{~mm}$. Existing tunnels supported by concrete liner with the thickness $350 \mathrm{~mm}$, rebar of steel $d=22 \mathrm{~mm}$; spacing of rebar $250 \mathrm{~mm}$. The length of the numerical model is $113.2 \mathrm{~m}$ and the height $66.5 \mathrm{~m}$ respectively (Figure 9). The all boundaries of the model are applied to the fixed conditions to simulate the real application. Here, the values of equivalent blasting pressures are applied in the model by distributed loads $(P)$ in new tunnels from $1 \mathrm{MPa} ; 2 \mathrm{MPa}$ to $12 \mathrm{MPa}$, the weight of explosion at the same time $\mathrm{Q}=50-150 \mathrm{~kg}$ respectively.

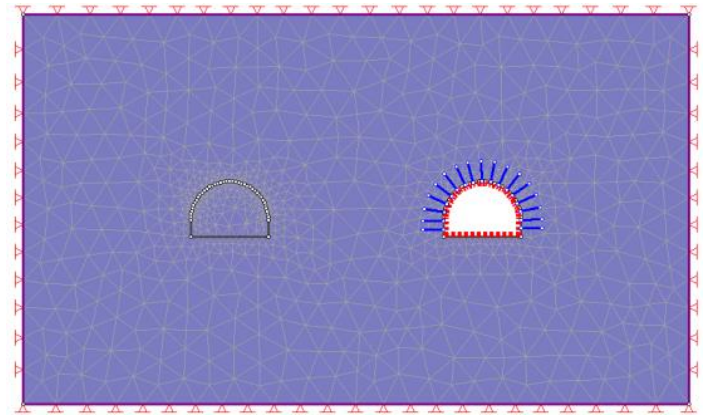

(a) Initial model without new tunnel

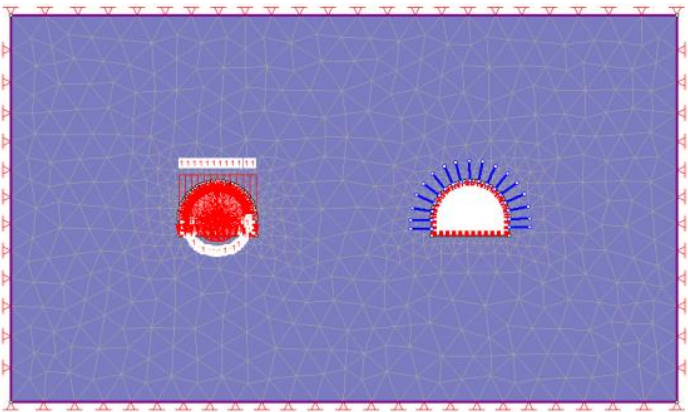

b) After excavation blasting new tunnel

Fig. 9 - Numerical modeling for excavation new tunnel using equivalent blasting pressure and existing tunnels in Co Ma pass project in Viet Nam

The research results (Figures.10-14) indicate that the values on the vertical axis which located in the left corner of existing tunnels, the minimum displacements located in the rightwall of old tunnel respectively, the maximum values of displacements are investigated on the floor near the left corner of existing tunnels. Basing the assessment standards for the stability of tunnels, if the values of displacements of rock mass around tunnels and concrete lining are bigger than 


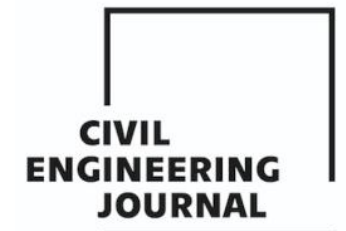

Article no. 4

THE CIVIL ENGINEERING JOURNAL 1-2021

limited values, the concrete lining will be cracked. The results of research also show that in case of using equivalent blasting pressure $7 \mathrm{MPa}$ the internal forces in the concrete liner of existing tunnel are negligibly changed. It is necessary to use some solutions for blasting technologies to reduce blasting vibration on the existing tunnel and the weight of explosion in new tunnel will be less than $50 \mathrm{~kg}$ respectively.

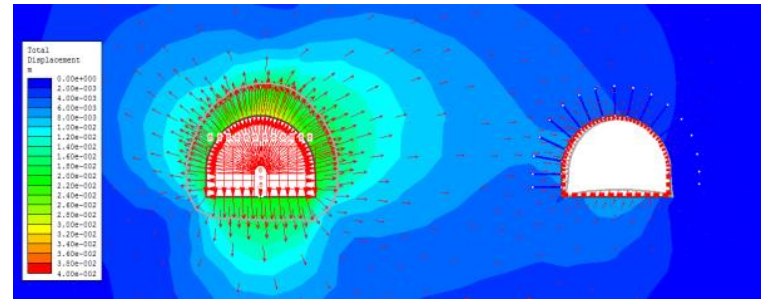

(a) Displacement vector in case of equivalent blasting pressure $P=6 \mathrm{MPa}$

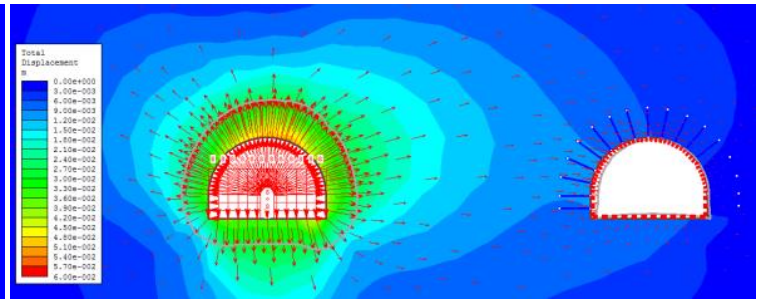

(b) Displacement vector incase of equivalent blasting pressure $P=8 \mathrm{MPa}$

Fig. 10 The distribution of displacement vector in rock mas around two tunnels

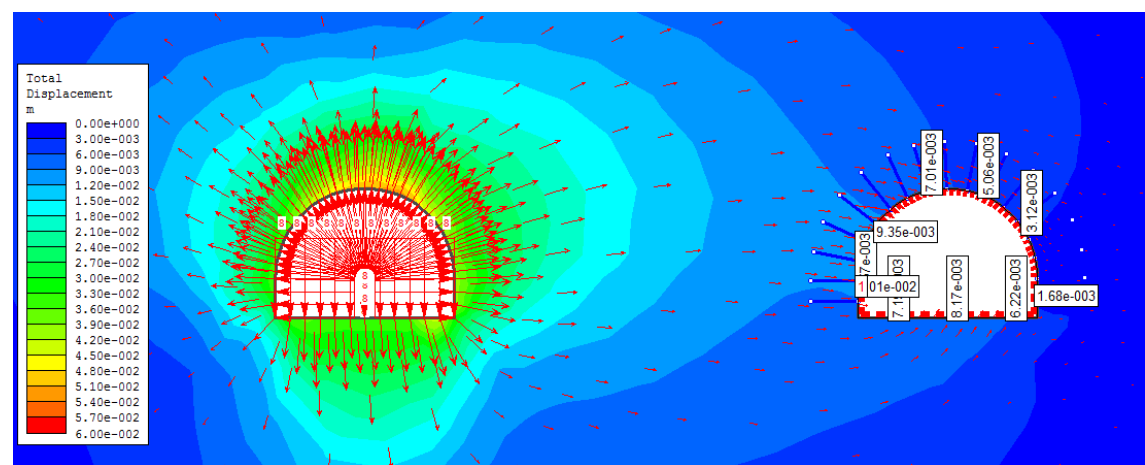

Fig. 11 - The values of displacement on the boundary of existing tunnel in case of $P=6 \mathrm{MPa}$

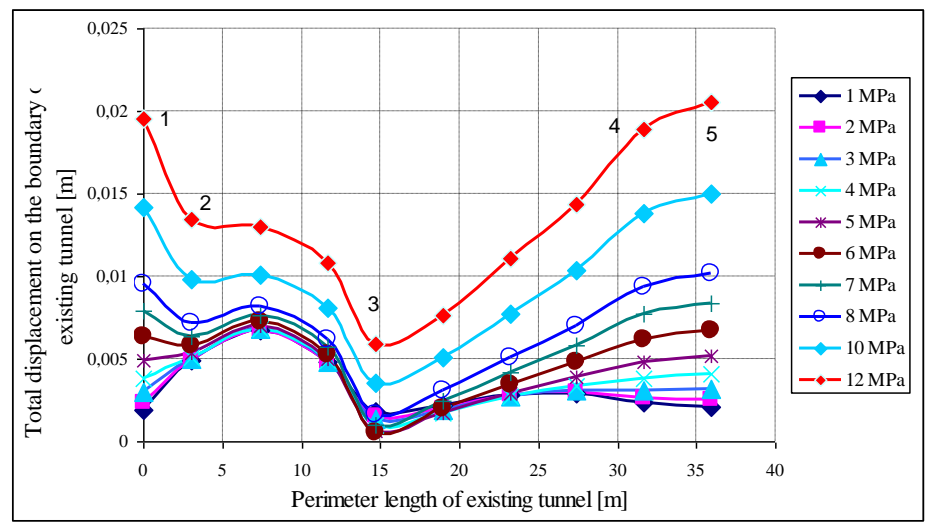

Fig. 12 - The changing of displacements of rock mass on the boundary of existing tunnel 


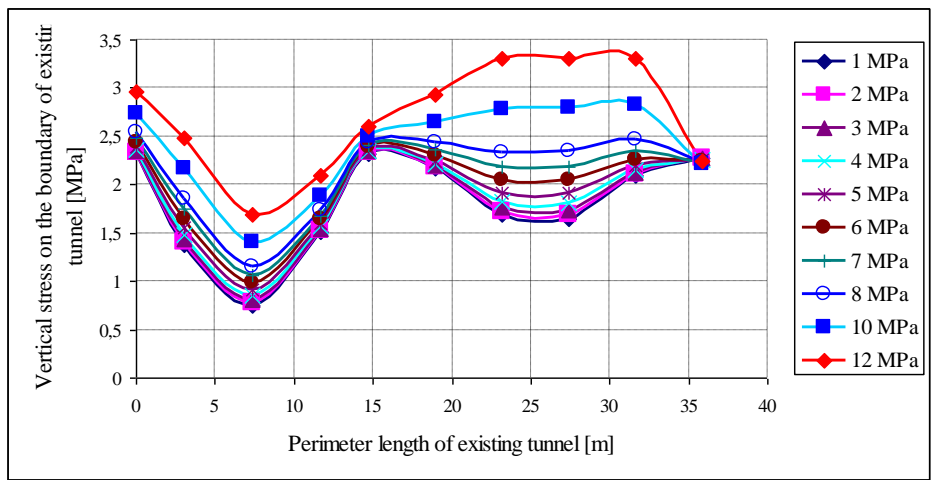

Fig. 13 - The relationship between vertical stress in rock mass around existing tunnel

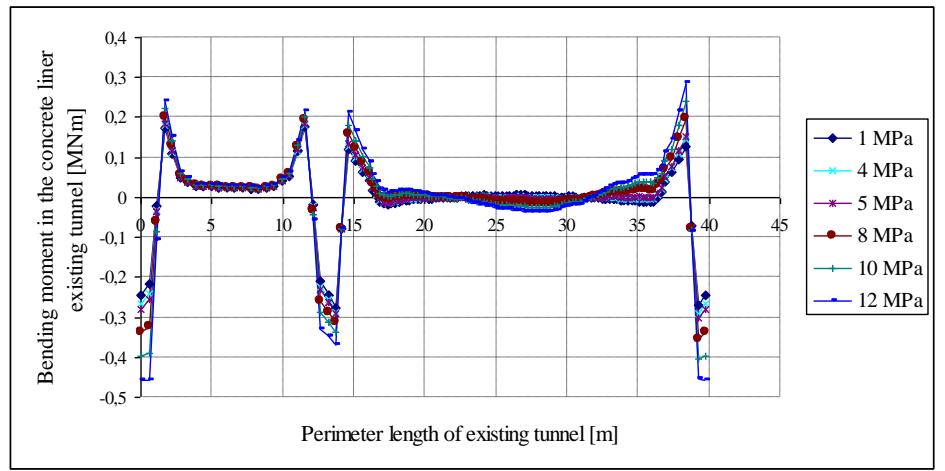

Fig. 14 - The changing bending moments in the concrete lining of existing tunnel

\section{NUMERICAL MODEL IN CASE OF EXPANSION BLASTING THE AUXILIARY TUNNEL NEAR THE OLD TUNNELS IN HAI VAN PASS PROJECT OF VIETNAM}

Hai Van pass project located between Thua Thien Hue and Da Nang provinces of Vietnam, main tunnel was finished in 2005 with the total length of tunnel $6280 \mathrm{~m}$ with twin parallel tunnels, 4 lanes in each tunnel, and two ventilation shafts. Main tunnel has total length $6280 \mathrm{~m}$, span of tunnel $13 \mathrm{~m}$, the distance between main tunnel and auxiliary tunnel is $30 \mathrm{~m}$, area of auxiliary tunnel before expansion is $15,5 \mathrm{~m}^{2}$, the height of auxiliary tunnel $4.5 \mathrm{~m}$, span 5.3 respectively, View 3D for Hai Van tunnel project can be seen as in (Figure 15).

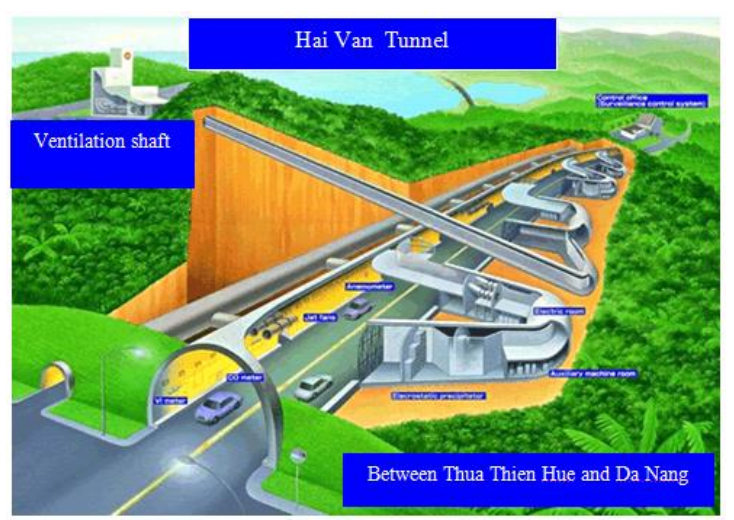

Fig. 15 - View 3D for Hai Van tunnel in Viet Nam

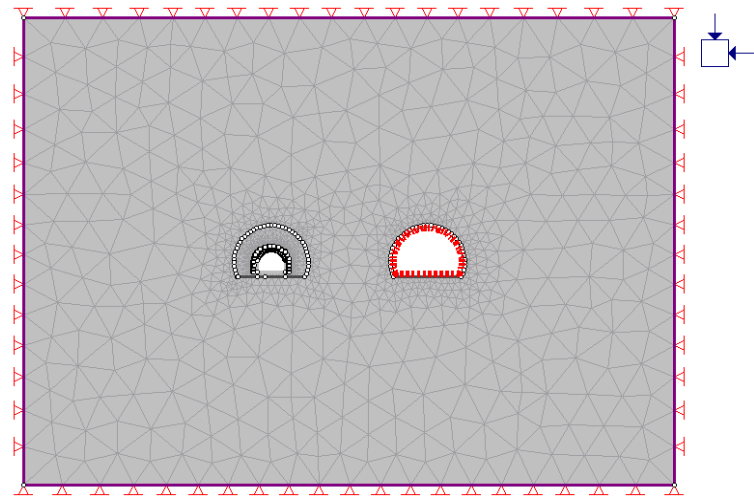

Fig. 16 - Numerical modeling by Phase 2 
In this study numerical a method will be used for analysis. Because of the difference of the geological conditions along tunnels to model for research is chosen the range of quality of rock mass with RMR ratio in the catalogues of Bieniawski RMR $=60-80$. Base on the results of investigation for rock mass conditions and profile of the auxiliary tunnel with span $5.3 \mathrm{~m}$ and height $4.5 \mathrm{~m}$. In the main tunnel concrete lining has the thickness $35 \mathrm{~cm}$, rebar with diameter $\mathrm{d}=22 \mathrm{~cm}$, and space of rebar reinforcement $a=20 \mathrm{~cm}$. Using numerical method PHASE 2 can be received model in this case as in the (Figure16). In the case study using the dimension of external boundary of model is $125 \mathrm{~m}$ and height $90 \mathrm{~m}$, number of nodes and elements in model 14438, 24710 respectively, equivalent blasting pressure in this model can be defined by formula:

$$
\mathrm{P}=0,00337 \rho v^{2}
$$

Where:

\section{$P$ - Blasting pressure, psi; $\rho$ - Density of explosion; $v$ - Velocity of explosion, fps.}

Its assumption that the blasting pressure in the holes of drilling pattern in the auxiliary tunnel before expansion from existing profile to the design profile of tunnel are replaced from 7 to $20 \mathrm{MPa}$ as in the (Figure 17).

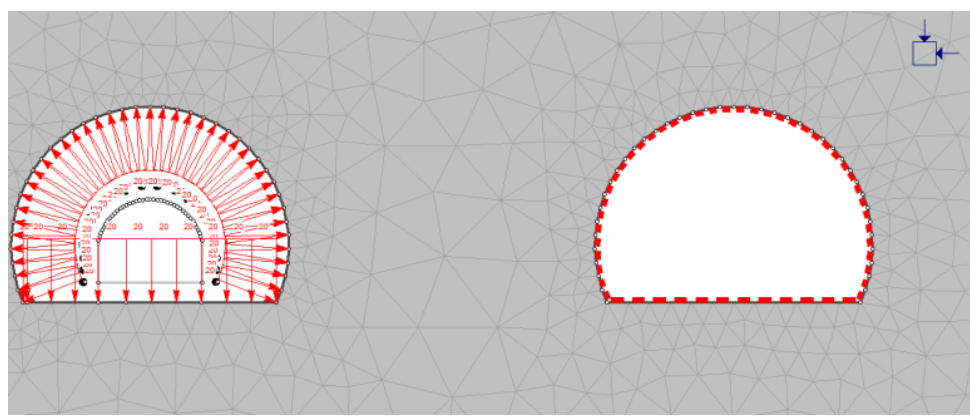

Fig. 17 - Numerical simulation for expansion the auxiliary tunnel of Hai Van in case of $P=20 \mathrm{MPa}$

Based on the values of internal forces in concrete lining of main tunnel when changing the values of blasting pressure during excavation expansion the auxiliary tunnel are calculated the minimum values of blasting pressure effecting on the linings of existing support in the main tunnel of Hai Van pass project. The results of the distribution of displacement vector and zone damage of explosion around the auxiliary tunnel and main tunnel when changing the values of equivalent blasting pressure can be shown as in (Figure18).

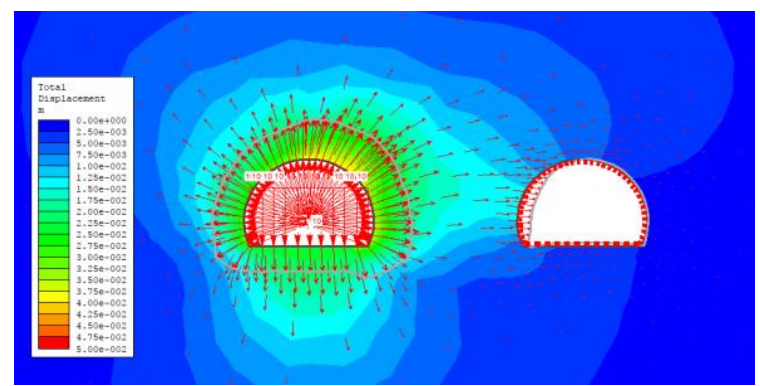

(a) The distribution of displacement vector

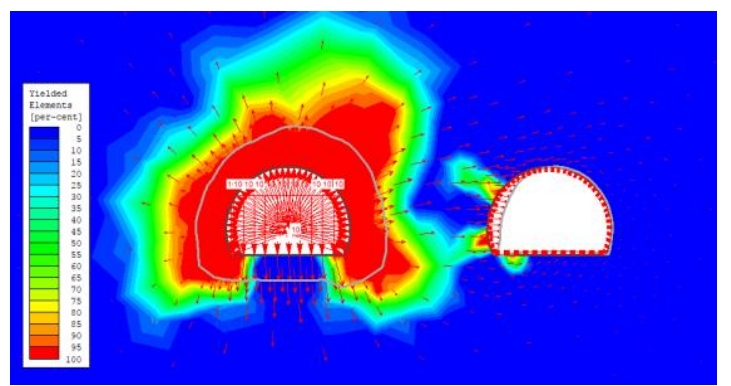

(b) zone damage of explosion

Fig. 18 -The results of displacement vector and zone damage of explosion around the auxiliary tunnel in case of blasting pressure 10MPa in Hai Van pass

To assessment the changing internal forces in the concrete lining of existing tunnel of Hai Van pass project, established the relationship between the values of blasting pressure in the 
auxiliary tunnel and the internal forces of concrete lining in the existing tunnel. Research results can be seen as in the (Figures.19-21).

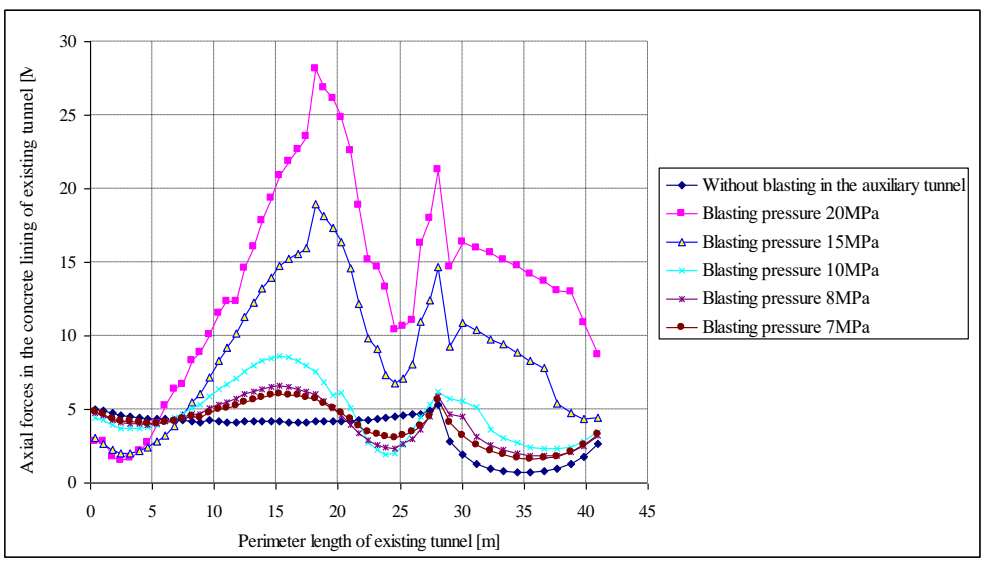

Fig. 19 - Alternation of axial force in the concrete lining of existing tunnel before and after expansion blasting the auxiliary tunnel

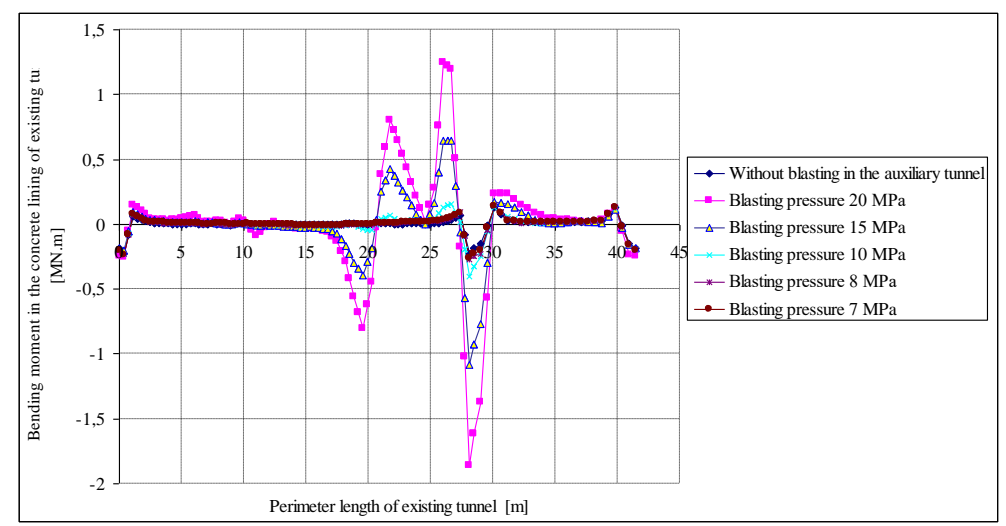

Fig. 20 - Changing bending moment in the concrete lining of existing tunnel before and after expansion blasting the auxiliary tunnel

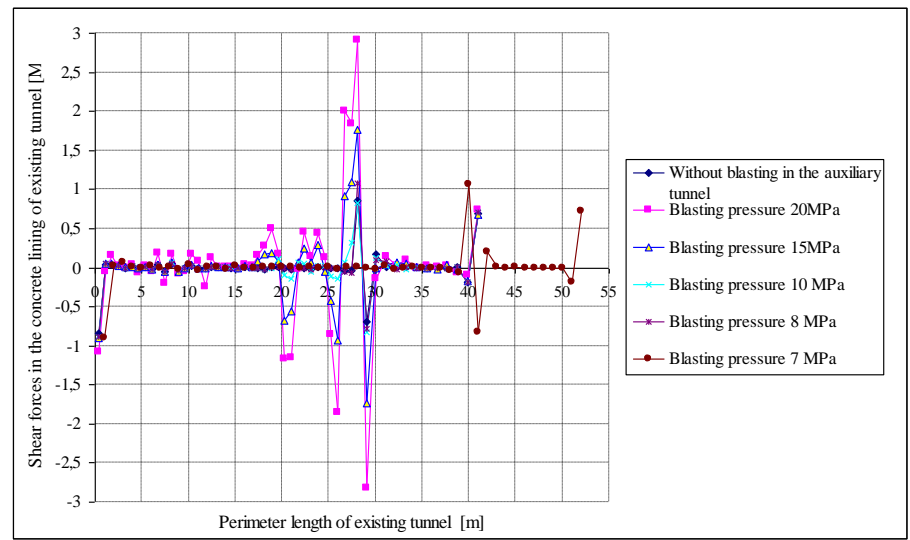

Fig. 21 - Variation of shear forces in the concrete lining of existing tunnel before and after expansion blasting the auxiliary tunnel

Results in the (Figures19-21) show that, if the values of internal forces in the concrete lining in old tunnel are equal these values in the lining before expansion blasting the auxiliary tunnel, can 
be received optimal blasting pressure during blasting in the auxiliary tunnel. Results can also show that, in case study the values of blasting pressure $7 \mathrm{MPa}$ is optimal. Base on this value should have to control blasting solution to reduce blasting pressure on the boundary of auxiliary tunnel will be less than $7 \mathrm{MPa}$.

\section{NUMERICAL MODELING THE STABILITY OF CONCRETE LINER IN THE EXISTING RAILWAY IN CO MA PASS PROJECT}

In this section present the effects of blasting vibration on the stability of concrete liner of railway tunnel in the geological conditions of Co Ma pass project. Railway tunnel was built 100 years ago by France, tunnel located Km 1234+464 in Dai Lanh commune, Van Ninh district, Khanh Hoa province. Height of railway tunnel $4.0 \mathrm{~m}$, span of tunnel $4.33 \mathrm{~m}$ respectively. Site plan of railway tunnel $\mathrm{N}^{0} 24$, Co Ma transported tunnel and profiles of them can be seen as in the (Figures 22-24). Railway tunnel was supported by concrete liner, the properties of rock mass around railway tunnel and support liner can be seen such as [9]:

Properties of back fill around concrete liner (Silstone - 1): Poisson ratio $v=0.331$; Unit weight of back fill material $\gamma=0.0255 \mathrm{MN} / \mathrm{m}^{3}$; Friction angle $\varphi=18$ Degree; Young modulus $E=$ $1583 \mathrm{MPa}$; Cohesion $\mathrm{c}=0.36 \mathrm{MPa}$.

Properties of rock mass around railway tunnel (2): Uniaxial compressive strength of intact rock $\sigma_{c i}=80 \mathrm{MPa}$; Unit weight of rock mass $\gamma=0.0255 \mathrm{MN} / \mathrm{m}^{3}$; Tensile strength $\sigma_{t}=0.3 \mathrm{MPa}$; Cohesion $\mathrm{c}=1.0 \mathrm{MPa}$; Friction angle $\varphi=25$ Degree; Young modulus $\mathrm{E}=5000 \mathrm{MPa}$; Poisson ratio $\mathrm{v}=0.293$; Residual friction angle $\mathrm{c}_{\mathrm{re}}=22$ Degree; Span of roadways $\mathrm{B}=13.2 \mathrm{~m}$; Height of tunnels $\mathrm{H}=9.5 \mathrm{~m}$; Depth of tunnels, $70 \mathrm{~m}$; Lateral earth pressure coefficient $\mathrm{K}_{0}=1.0$.

Properties of old concrete liner in railway tunnel (3): Poisson ratio $v=0.3$; Unit weight of concrete liner $\gamma=0.022 \mathrm{MN} / \mathrm{m}^{3}$; Young modulus $\mathrm{E}=3000 \mathrm{MPa}$.

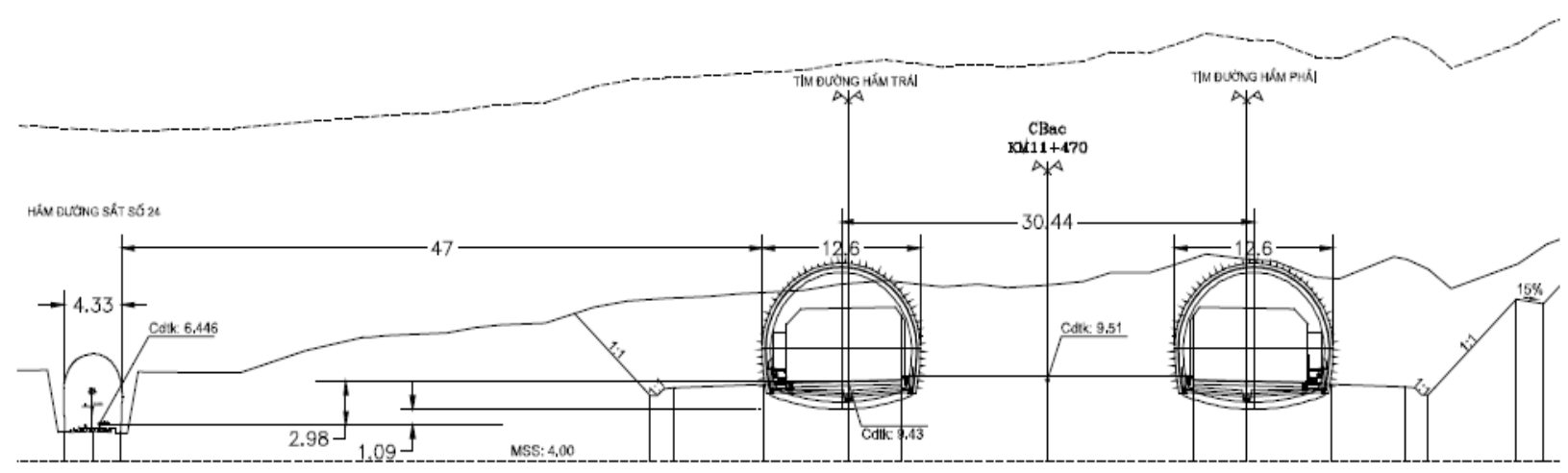

Fig. 22 - Profile of railway tunnel $N^{0} 24$ and transported tunnel under Ca pass [9]. 


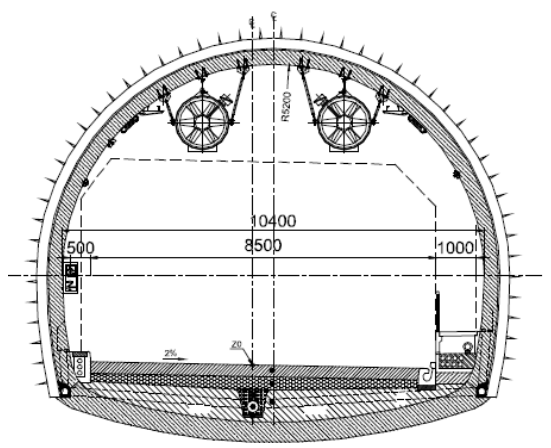

Fig. 23 - Profile of new transported tunnel

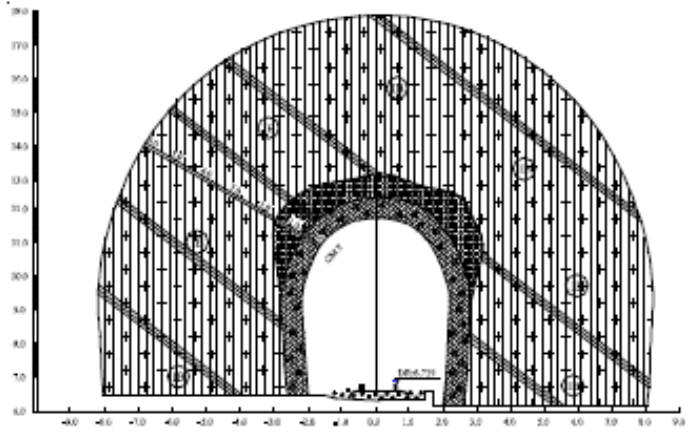

Fig. 24 - Profile of existing railway tunnels $\mathrm{N}^{0} 24$

Using numerical method in Phase 2 can be received model in this case as in (Figure 25). In the case study using the dimension of external boundary of model is $113.2 \mathrm{~m}$ and height $66.5 \mathrm{~m}$, number of nodes and elements in model 2092, and 4020 in case of without new transported tunnel, and 1974 nodes and 3720 elements respectively when creating a new transported tunnel in the model as in the Figures 25 and 26. The conditions of external boundary of model are chosen fixed strain such as in the rock mass far from boundary of new tunnel the stress will be initial values.

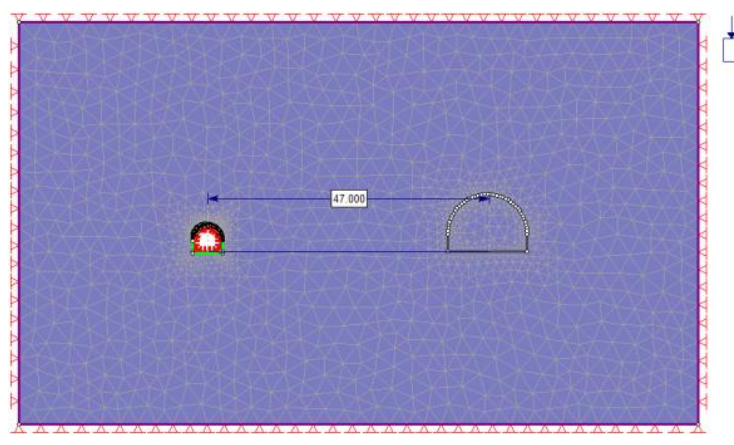

Fig. 25 - Model of railway tunnel without new Co Ma transported tunnel

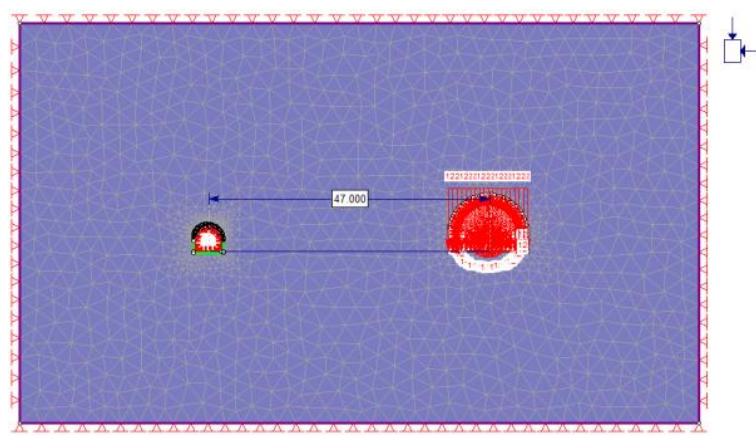

Fig. 26 - Equivalent blasting pressure in new tunnel and existing railway tunnel $\mathrm{N}^{0} 24$

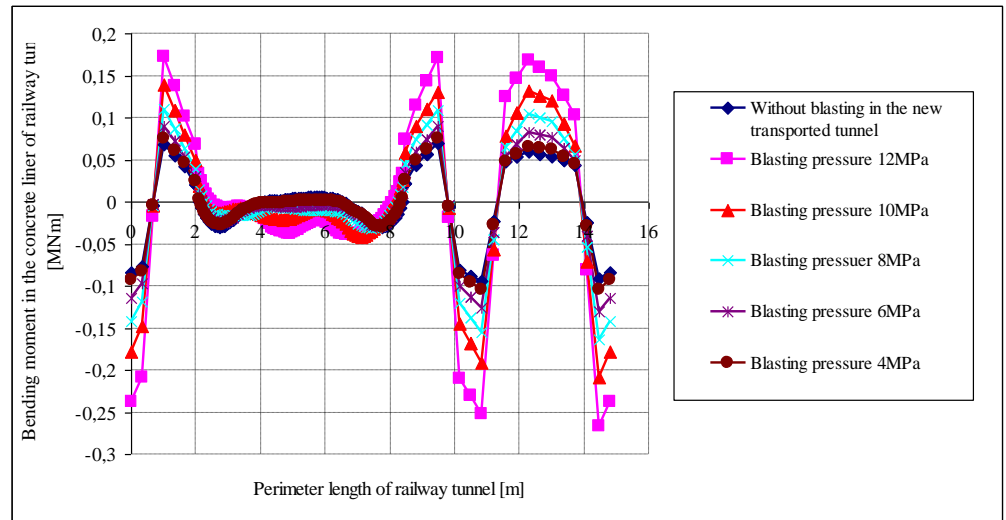

Fig. 27 - The changing of bending moment in the concrete liner of existing railway $N^{0} 24$ with other values of equivalent blasting pressure in new transported tunnel Co Ma. 


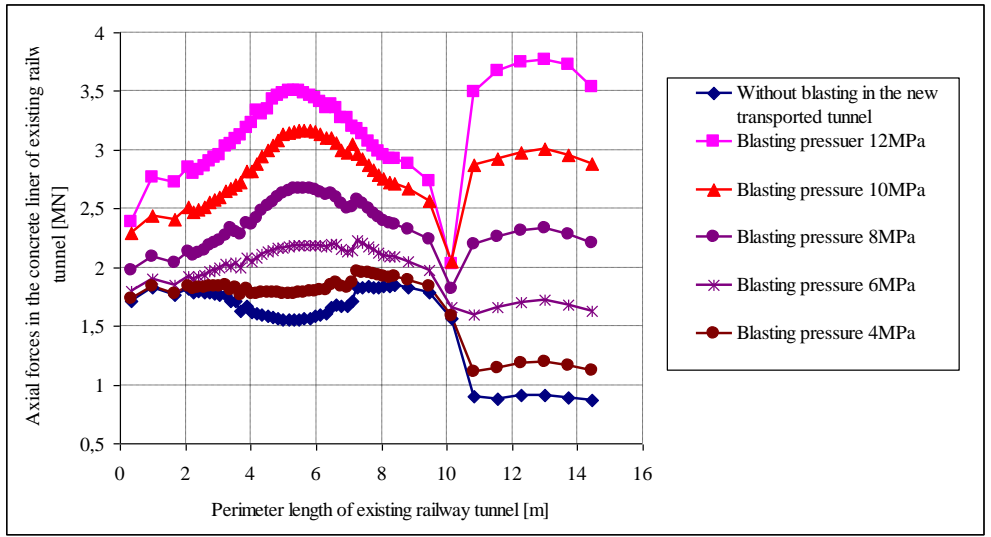

Fig. 28 - Axial forces in concrete liner of existing railway tunnel

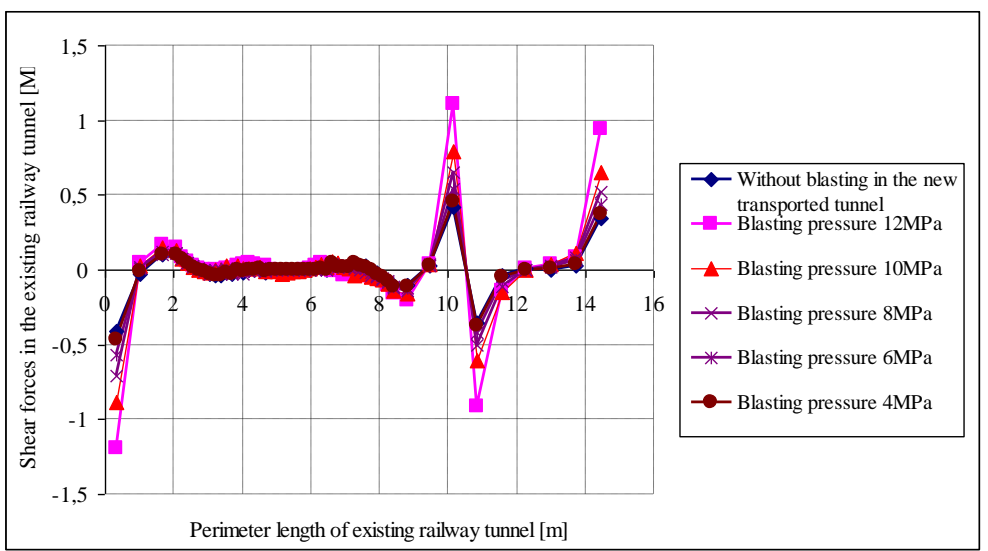

Fig. 29 - Shear forces in concrete liner of existing railway tunnel

Results in (Figures 27-29) can show that, the values of internal forces in the concrete liner of existing railway tunnel are the same as these values of this concrete liner in case of without new transported tunnel, the values of blasting pressures will be optimal. By research results can be received the optimal blasting pressure in this case $4 \mathrm{MPa}$, the equivalent weight of explosion at the same time during excavation new tunnel approximately $42 \mathrm{kgs}$ explosion of P3151.

\section{EXPERIMENTAL INVESTIGATION OF THE RESULTS}

In the experiences excavation tunnels contour and smooth blasting methods can be used to reduce effects vibration of blasting during expansion the auxiliary tunnel on the stability of concrete lining in the existing tunnel in Hai Van pass project in Vietnam. In this project recommended using characteristics of drilling and blasting parameters of drilling pattern such as in (Tables.2-3).

Experimental blasting in Hai Van pass project shows that, when using optimal blasting pressure $7 \mathrm{MPa}$ on the contour of the auxiliary tunnel, the values of internal forces in concrete lining of existing tunnel in Hai Van are not change. In the case study the density of explosion in each hole is less than $1 \mathrm{~kg}$, total density of explosion at the surface of tunnel less than $45 \mathrm{kgs}$. The results of explosion of project can be shown as in figs.30-32. 
Article no. 4

THE CIVIL ENGINEERING JOURNAL 1-2021

ENGINEERING

JOURNAL

Tab. 2 - Parameters of drilling and blasting pattern recommended during expansion the auxiliary tunnel in Hai Van Pass project of Viet Nam

\begin{tabular}{|c|l|c|c|c|}
\hline $\mathrm{N}^{0}$ & \multicolumn{1}{|c|}{ Parameters } & Symbol & Values & Units \\
\hline 1 & Length of holes & $\mathrm{L}_{\mathrm{k}}$ & 1. & $\mathrm{~m}$ \\
\hline 2 & Spacing holes & $\mathrm{W}$ & 0.8 & $\mathrm{~m}$ \\
\hline 3 & Specific charging of explosion & $\mathrm{q}$ & $\mathrm{kg} / \mathrm{m}^{3}$ & 0.8 \\
\hline 4 & Total density of explosion & $\mathrm{Q}$ & $\mathrm{kg}$ & 42.75 \\
\hline 5 & Total number of blast holes in the surface & $\mathrm{N}$ & 98 & $\mathrm{holes}$ \\
\hline 6 & The length of explosive in the holes & $\mathrm{L}_{e}$ & 0.6 & $\mathrm{~m}$ \\
\hline 7 & The uncharged length in the cut holes & $\mathrm{L}_{\mathrm{u}}$ & 0.7 & $\mathrm{~m}$ \\
\hline 8 & $\begin{array}{l}\text { The length of explosive in the holes in the } \\
\text { contuor holes }\end{array}$ & $\mathrm{L}_{3}$ & 0.3 & $\mathrm{~m}$ \\
\hline 9 & The uncharged length in the contuor holes & $\mathrm{L}_{c}$ & 1.0 & $\mathrm{~m}$ \\
\hline
\end{tabular}

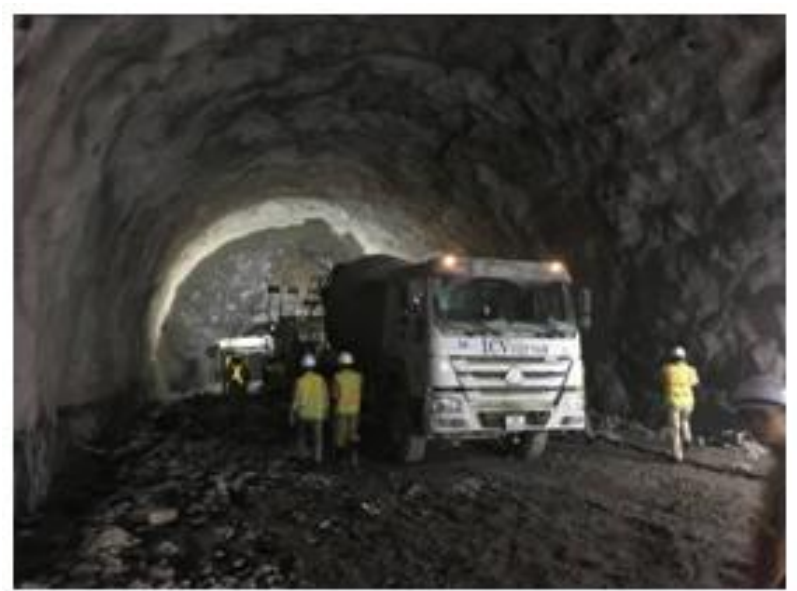

Fig. 30 - Drilling and blasting works when expansion the auxiliary tunnel in Hai Van project

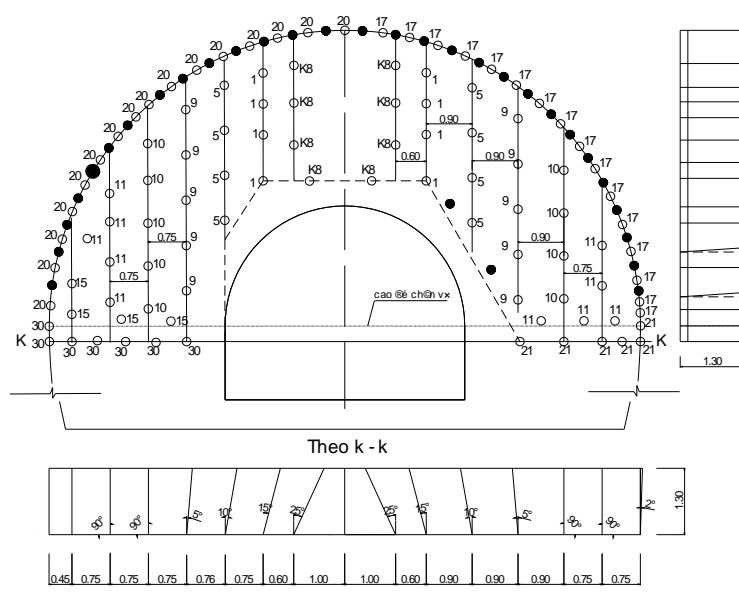

Fig. 31 - Holes pattern in the surface of the auxiliary tunnel

Tab. 3 - Characteristics of holes in the face of auxiliary tunnel

\begin{tabular}{|c|c|c|c|c|c|c|c|c|c|c|c|c|c|}
\hline \multirow[t]{2}{*}{$\mathrm{N}^{0}$} & \multirow[t]{2}{*}{$\begin{array}{l}\text { Number of } \\
\text { blast holes }\end{array}$} & \multirow[t]{2}{*}{ Holes } & \multirow{2}{*}{$\begin{array}{c}\text { Electri } \\
\text { cal } \\
\text { detona } \\
\text { tor }\end{array}$} & \multirow[t]{2}{*}{$\begin{array}{l}\text { Time } \\
\text { delay }\end{array}$} & \multirow[t]{2}{*}{$\begin{array}{c}\text { hole } \\
\mathrm{s}\end{array}$} & \multirow{2}{*}{$\begin{array}{c}\text { length } \\
\text { of } \\
\text { holes }\end{array}$} & \multicolumn{3}{|c|}{$\begin{array}{c}\text { Total density of } \\
\text { explosion, kg }\end{array}$} & \multirow{2}{*}{$\begin{array}{c}\text { The } \\
\text { uncharge } \\
\text { d length, } \\
\text { m }\end{array}$} & \multirow{2}{*}{$\begin{array}{l}\text { Leng } \\
\text { th of } \\
\text { hole } \\
s\end{array}$} & \multicolumn{2}{|c|}{$\begin{array}{c}\text { Angle of } \\
\text { holes, degree }\end{array}$} \\
\hline & & & & & & & $\begin{array}{l}\text { one } \\
\text { hole }\end{array}$ & $\begin{array}{c}\text { total } \\
\text { densi } \\
\text { ty }\end{array}$ & $\begin{array}{l}\text { total } \\
\text { holes }\end{array}$ & & & $\begin{array}{l}\text { Ver } \\
\text { tica } \\
\text { I }\end{array}$ & $\begin{array}{c}\text { Horizo } \\
\text { ntal }\end{array}$ \\
\hline 1 & fire hole 1 & $1-8$ & 1 & 25 & 2 & 1.3 & 0.6 & 4.8 & 8 & 0.7 & 5.6 & 90 & 115 \\
\hline 2 & fire hole 2 & $9-16$ & 5 & 125 & 2 & 1.3 & 0.6 & 4.8 & 8 & 0.7 & 5.6 & 105 & 105 \\
\hline 3 & fire hole 3 & $17-24$ & 9 & 250 & 1.5 & 1.3 & 0.45 & 3.6 & 8 & 0.85 & 6.8 & 90 & 100 \\
\hline 4 & fire hole 4 & $25-34$ & 11 & 350 & 1.5 & 1.3 & 0.45 & 4.5 & 10 & 0.85 & 8.5 & 90 & 95 \\
\hline 5 & fire hole 5 & $34-41$ & 13 & 450 & 1 & 1.3 & 0.3 & 2.4 & 8 & 1 & 8 & 90 & 90 \\
\hline 6 & fire hole 6 & $42-51$ & 15 & 600 & 1 & 1.3 & 0.3 & 3.3 & 11 & 1 & 11 & 90 & 90 \\
\hline 7 & contour holes & $52-66$ & 17 & 800 & 1 & 1.3 & 0.3 & 4.8 & 16 & 1 & 16 & 90 & 92 \\
\hline 8 & lifter holes 1 & $67-75$ & 20 & 1125 & 1 & 1.3 & 0.3 & 4.8 & 16 & 1 & 16 & 90 & 92 \\
\hline 9 & lifter holes 2 & $76-80$ & 21 & 1225 & 2.5 & 1.3 & 0.75 & 4.5 & 6 & 0.55 & 3.3 & 90 & 92 \\
\hline 10 & lifter holes 2 & $81-98$ & 30 & 4350 & 2.5 & 1.3 & 0.75 & 5.25 & 7 & 0.55 & 3.85 & 90 & 92 \\
\hline & Total & & & & & & & 42.75 & 98 & & & & \\
\hline
\end{tabular}



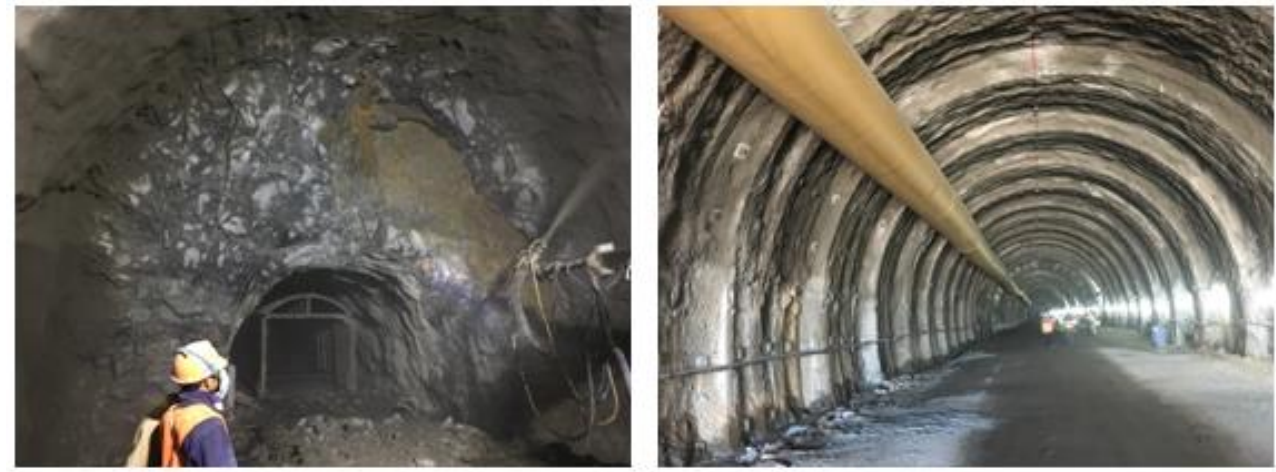

Fig. 32 - Investigation blasting results after expansion the auxiliary tunnel in Hai Van pass project

\section{CONCLUSION AND DISCUSSION}

The above research results can show that, blasting vibration during excavation new tunnels has influence on the stability of rock mass around existing tunnel such as the stability of support lining of existing tunnel. Blasting vibration can be replaced by equivalent blasting pressure in the numerical modelling which impact on the stability such as displacements, stress on the boundary of old tunnel, and the values of internal forces in the support liner of existing tunnel.

Based on the determination of the optimal values of equivalent blasting pressures can be explained that the existing tunnel will be stable in case of drilling and blasting in the new tunnel has not influence on the values of internal forces in support liner of existing tunnel.

Experimental blasting in Hai Van pass project shows that, when using optimal blasting pressure $7 \mathrm{MPa}$ on the contour of the auxiliary tunnel, the values of internal forces in concrete lining of existing tunnel in Hai Van are not change. In case study the density of explosion in each hole is less than $1 \mathrm{~kg}$, total density of explosion for surface less than $45 \mathrm{kgs}$ and using 10 delay times for other holes group. The vibration of process blasting and drilling in the auxiliary tunnel have not influence on the stability of old linings.

The results of experimental blasting in Co Ma pass project in case of excavation new transported tunnel near the railway tunnel can indicate that, using optimal blasting pressure $4 \mathrm{MPa}$ on the contour of new tunnel, the drilling and blasting in new tunnel has not influence on the stability of old railway tunnel. The weight of explosion at the same time in new tunnel over $40 \mathrm{kgs}$.

Received results also show that in the practice when building new tunnels near the existing tunnel to reduce effects of vibration of blasting can be used other blasting solutions such as using many delay times between holes, types of electrical detonators, direction controls of vibration ways, arrangement of cut holes in the surface, using empty holes etc. In other words, appropriated drilling and blasting parameters must be controlled and used, both models for smooth and contour blasting are recommended in the contour of the auxiliary tunnels.

\section{REFERENCES}

[1] Vo Trong Hung, Le Dinh Tan, Nguyen Tien Khiem., 1999. Research on dynamic behaviors of rock mass and supports of tunnel under blasting wave. Journal of geotechnics, N01, Ha Noi. pp15-20.

[2] Le Dinh Tan (2000). The dynamic calculation of underground structures under impacting of blasting wave. Doctor thesis. Military Technical Academy, Ha Noi.

[3] Regulation of safety, maintain, using and transportation of industrial explosions. QCVN 02:2008/BCT.

[4] Nguyen Xuan Man et al (2010). Determination of failure zone diameter of single explosions in rock mass. Proceeding of the 19th conference Ha Noi University of mining and geology. Ha Noi.

[5] Nguyen Hai Hung et al (2014). The effects of delay time on the military structures. Proceeding of the 19th conference Ha Noi university of mining and geology. Ha Noi. 
[6] Dang Van Kien (2014). Investigation blasting vibration during excavation tunnel by drilling and blasting method in the urban conditions by two-dimension model. Journal of mining industrial. N06, Ha Noi. pp7-12.

[7] Dang V.K., Dias D., Do N.A., Vo T.H. (2018), Impact of Blasting at TunnelFace on an Existing Adjacent Tunnel. International Journal of GEOMATE, July, 2018 Vol.15, Issue 47, pp.22-31, 2018.

[8] Dam Trong Thang, Bui Xuan Nam, Tran Quang Hieu. Blasting in mining and structures. Publishing house of natural and technology science. Ha Noi 2014. 454p.

[9] Nguyen Hieu Nghia, Nguyen Duc Thuan (2016). Some problems for safety during excavation transported tunnels through the mountain by NATM using blasting near the operated buildings, Centre TVTK KCCT-TEDI. Designastion and consultion information - N0III/2016, pp34-45.

[10] Martin stolárik (2008). Modeling of vibration effect within small distances, Acta Geodyn. GEOMATE, Vol.5, No.2 (150), 137-146.

[11] Jens Anders Brenne Volden Engineering (2015). Geological evaluation of the applicability of Drill \& Split in tunnels at the Follo line project. Norwegian University of Science and Technology. June 2015.

[12] Jinxing Lai, ${ }^{1,2}$ Haobo Fan, ${ }^{2}$ Jianxun Chen, ${ }^{1,2}$ Junling Qiu, ${ }^{2}$ and KeWang ${ }^{2}$. ${ }^{1}$ Shaanxi Provincial Major Laboratory for Highway Bridge \& Tunnel, Chang'an University, Xi'an 710064, China; ${ }^{2}$ School of Highway, Chang'an University, Xi'an 710064, China. Blasting Vibration Monitoring of Undercrossing Railway Tunnel Using Wireless Sensor Network. 10 March 2015.

[13] Qingguo Liang Jie Li• Dewu Li• Erfeng Ou. Effect of Blast-Induced Vibration from New Railway Tunnel on Existing Adjacent Railway Tunnel in Xinjiang, China. Rock mechanics and rock engineering. January 2012.

[14] Мангуш С.К, Крюков Г.М, Фисун А.П (2000). Взырвные работы при подземной разработке полезных ископаемых, Москва 2000. 